\title{
High-temperature investigation of mould slag crystallization by single and double hot thermocouple techniques
}

\author{
Nathalie Kölbl ${ }^{1}$ (D) Irmtraud Marschall ${ }^{1} \cdot$ Harald Harmuth $^{1}$
}

Received: 7 December 2018/Revised: 1 January 2019/Accepted: 11 January 2019/Published online: 2 April 2019

(C) The Author(s) 2019

\begin{abstract}
Methods for the characterization of mould slag crystallization with special emphasis on the single/double hot thermocouple technique (SHTT/DHTT) are reviewed. In the continuous casting process of steels, horizontal heat transfer is mainly influenced by the crystallization behaviour of the mould flux film. Here, both precipitation of crystals out of a liquid phase and devitrification of the glassy film in contact with the mould are of main interest. Therefore, various investigation methods are implemented to characterize different slag properties related to crystallization: a viscometer for determining the break temperature, differential thermal analysis (DTA), confocal scanning laser microscopy, and the water-cooled copper finger test. For near-service conditions, DHTT reveals the most detailed information, including not only the crystallization or devitrification temperature but also the morphology as well as the crystallization velocity. Due to improvements in the device and the representation of the results, a comparison of different samples is possible. Nevertheless, the application field of SHTT/DHTT is restricted to slag systems with low contents of evaporating components. Furthermore, the time required for data analysis is significantly longer than that required for other methods, e.g. DTA. Therefore, the application of DHTT is mainly advisable for mould slag research and development, whereas DTA can also be used for incoming inspections.
\end{abstract}

Keywords Single hot thermocouple technique $\cdot$ Double hot thermocouple technique $\cdot$ Mould slag $\cdot$ Near-service condition . In situ investigation · Crystallization

\section{Introduction}

In the continuous casting process of steels, the mould slag is entrapped in the gap between the mould wall and the strand. In the meniscus area, the flux viscosity influences slag entrapment and, subsequently, mould lubrication. The slag film between the strand and the mould is divided into three layers: a liquid layer in contact with the strand, a glass at the mould side, and a crystalline layer in between [1]. The ability to form crystals, the crystalline structure and the crystalline fraction depend not only on the chemical composition of the slag but also on the temperature conditions during the operation. Because the structure of

Nathalie Kölbl

nathalie.koelbl@unileoben.ac.at

1 Department Mineral Resources Engineering, Chair of Ceramics, Montanuniversitaet Leoben, Leoben 8700, Styria, Austria the solidified slag film mainly affects the horizontal heat transfer and, furthermore, the strand quality [2], attention has been focused on investigating the crystallization behaviour. Crystallization from a liquid phase has been studied for decades [3-7]. Nevertheless, this process is only valid for the middle area of the slag film. In contrast, recent studies [8-11] have focused on the devitrification of crystals from the glassy phase, which is formed upon contact with the water-cooled copper mould immediately after infiltration. With increasing casting time, partial reheating of this glassy area occurs and enables the crystal formation, which in turn influences the heat transfer throughout the whole slag film [8]. Therefore, various methods are used to investigate the crystallization behaviour of the slags.

Differential thermal analysis (DTA) enables the detection of exothermal and/or endothermal reactions that occur when a sample is exposed to a defined temperature program. Generally, cooling rates of $5-20 \mathrm{~K} / \mathrm{min}$ are used [12-15]. For investigations of the crystallization process, 
$\mathrm{Pt} / \mathrm{Rh}$ or, in some cases, graphite crucibles are used. However, especially for platinum crucibles, the crucible surface roughness influences the precipitation of the first crystals. To overcome this disadvantage, a platinum wire is inserted into the crucible acting as nucleation sites and providing consistent conditions [16]. Using this method, information about the number of different crystal species and their crystallization temperature is obtained.

An example of a DTA result for a newly developed $\mathrm{CaO}-\mathrm{Al}_{2} \mathrm{O}_{3}$-based mould flux is given in Fig. 1 with different cooling rates [15]. In this diagram, two exothermal heat events are evident, indicating the formation of two different crystal species during the cooling. It can be seen that with increasing cooling rates, the highest peaks are shifted to lower temperatures.

This device is also used to identify the effects on the crystallization behaviour due to changes in the slag composition by reactions between the liquid slag and the steel (e.g. silica reduction by aluminium from the steel and absorption of alumina into the slag), because the curves representing the heat events and their temperature dependence can be easily compared. Furthermore, the recrystallization of a glassy sample during the reheating can be investigated, which is also observed for the glassy layer formed upon contact with the copper mould during the operation [17].

One of the most common investigation methods is the determination of the temperature dependence of the viscosity via the rotating cylinder method. During the cooling of the liquid with a defined temperature program, the torque of a cylindrical rotor at selected rotational speeds is measured. Based on these results, the viscosity, depending on the temperature, can be calculated from the torque. The break temperature, which is assumed to be the temperature

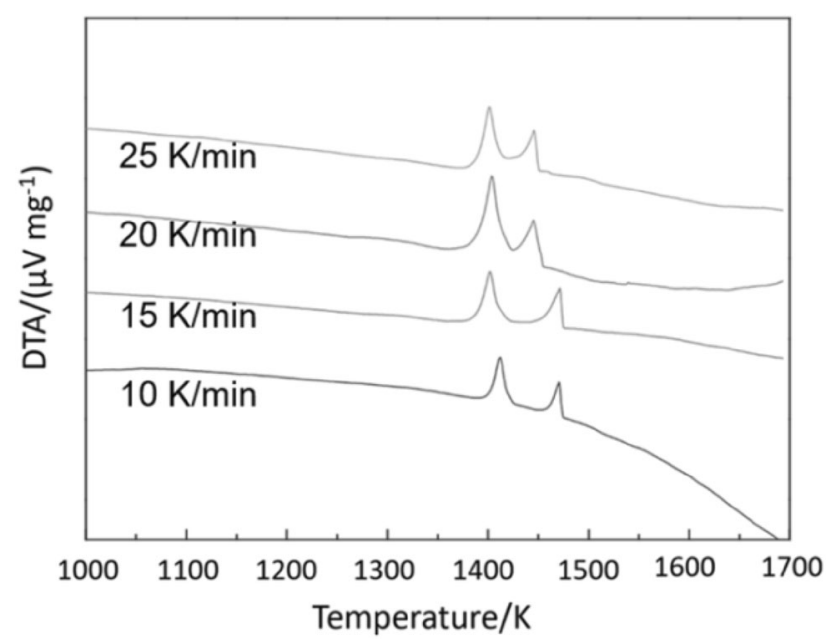

Fig. 1 DTA results for newly developed $\mathrm{CaO}-\mathrm{Al}_{2} \mathrm{O}_{3}$-based mould flux with various cooling rates (adapted from Ref. [15]) at which crystallization starts, is defined by the intersection of the two tangents of the curve branches [18-21].

The confocal scanning laser microscope (CSLM) enables the in situ observation of a mould slag [22-25]. If it consists of only small amounts of colouring oxides (e.g. $\mathrm{Fe}_{2} \mathrm{O}_{3}$ ), the precipitation of the first crystals is observed; otherwise, only crystallization at the slag surface can be detected, which does not necessarily mean that these are the first crystals formed out of the liquid phase. The sample is heated in a special furnace under a microscope. Its sample chamber is of oval shape and sputter coated with gold. The sample is located in the focus and is heated by a halogen bulb. The main advantages are the high heating rates (e.g. $1200 \mathrm{~K} / \mathrm{min}$ can easily be achieved), which reduce the evaporation of volatile components during the heating, as well as the high possible cooling speed, which enables the simulation of the first slag contact with the water-cooled copper mould. Furthermore, the application of laser provides an exceptional level of detail facilitating the observation of crystallization [26].

To emulate the contact of the liquid slag with the mould, a cold finger is immerged into the liquid slag pool for a defined dwell time. It is then removed, and the slag film solidified on its surface is investigated and compared with that of samples extracted from the continuous caster [27].

Even though all of these methods reveal important information regarding the crystallization behaviour of fluxes, an experimental set-up enabling the simulation of the temperature gradient between the mould and strand as well as simultaneous in situ observation of the slag film was necessary. Therefore, the single/double hot thermocouple technique (SHTT/DHTT) has been established by Kashiwaya et al. [28, 29] and further modified [30-32]. Thus far, a critical assessment of the set-ups used is given in the present paper.

\section{Experimental}

\subsection{Experimental set-up of SHTT/DHTT}

Based on the principle of the apparatus of Ordway [33] and Welch [34], SHTT/DHTT method was developed by Kashiwaya et al. [28, 29] for the in situ observation of crystallization in mould slag under isothermal (SHTT) or near-service (DHTT) conditions. The original set-up, which was only slightly modified in some cases, has been used by several research groups for mould flux characterization [35-46]. The devices include the experimental unit, the hot thermocouple drivers and a video capture system. A schematic of the experimental unit is shown in Fig. 2a. It consists of a sample chamber (5) housing the platinum wires made from B-type thermocouples welded without a 

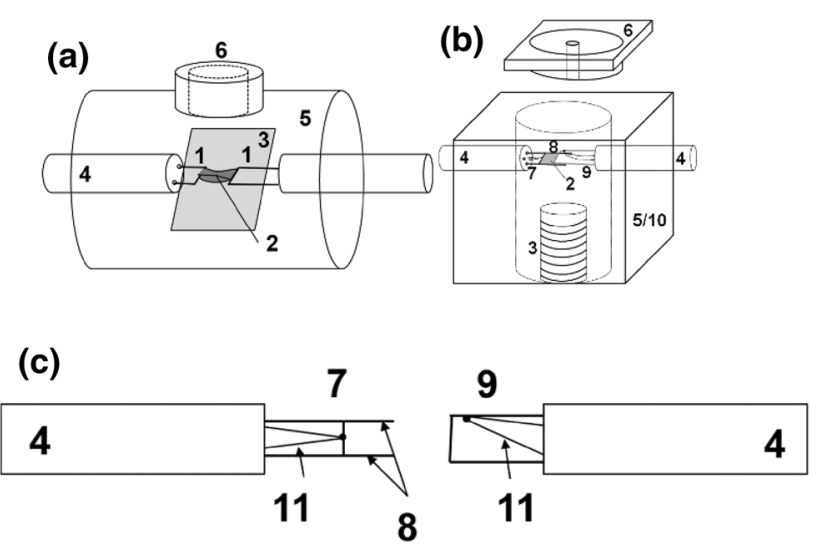

Fig. 2 Schematics of SHTT/DHTT devices according to Kashiwaya et al. [28] (a) and Kölbl et al. [32] (b, c). 1-U-shaped B-type thermocouple; 2-slag film; 3-additional heater; 4-ceramic rod of stretching device; 5-furnace chamber; 6-opening for observation; 7- $\mathrm{H}$-shaped platinum wire with additional B-type thermocouple (11); 8-leg of $\mathrm{H}$-shaped platinum wire; 9-U-shaped platinum wire with additional S-type thermocouple (11); 10-refractory lining; and 11-additional S-type thermocouple

bead (1). The wires are connected to the hot thermocouple driver, enabling simultaneous temperature measurement while the wire is heated. For this purpose, the rectification of the current into a half-wave using a silicon-controlled rectifier is required. Whereas one total half-period is used for heating, only $1 / 3$ of the subsequent period can be used for temperature measurement to reduce sample noise [28]. An additional heater (3) positioned near the sample reduces heat loss from the sample furnace to the surroundings $[31,32]$. To achieve higher cooling rates of the sample for isothermal experiments, the equipment may also include an air cooling device [38, 47].

Although SHTT and DHTT experimental set-ups had been improved since their establishment in the 1950s $[33,34]$, they still suffered from some deficiencies: The minimum of the temperature gradient is expected at the cold wire. However, thermal calculations of the temperature gradient within the slag film showed that the minimum is located somewhere in the middle. This finding is related to the heat loss from the sample surface to the surroundings [48]. Furthermore, U-shaped design of the thermocouples does not fulfil the requirements of sufficient stretching and leads to a droplet formation between the platinum wires, which impede the detection of crystals within a slag containing a certain content of colouring oxides (e.g. $\mathrm{Fe}_{2} \mathrm{O}_{3}$ ). To overcome these deficiencies, the set-up of the equipment was modified (Fig. 2b). The new device consists of a furnace chamber (5) heated to the cold wire temperature. The correct location of the minimum temperature at the cold wire was verified by thermochemical calculations and compared with mineralogical investigations after the experiment [32]. Due to the control of the heating of
U-shaped platinum wire (9) in close contact with the cold end of the slag film (see below), this approach contributes to a continuous temperature decrease within the slag film. In the case of other set-ups, additional heaters in the form of wire windings below the sample [28] or surrounding the slag film [21, 42] are used. Nevertheless, they cannot ensure a continuous temperature decrease from the hot to the cold wire.

The design of the platinum wires was also improved. Instead of two U-shaped thermocouples, one $\mathrm{H}$-shaped heating wire (7) and a U-shaped stretching device (9) are used. Contrary to the previously described thermocouples (1), additional S-type thermocouples (11) are welded to the heating wire (7) and the stretching device (9) in the new apparatus. In this case, the temperature measurement is separated from the heating cycle. Due to their special shapes, the stretching of a thin slag film within the legs of the $\mathrm{H}$ is possible. Thus, the crystallization of slags containing small amounts of colouring oxides can also be observed. Additionally, heating of U-shaped platinum wire (9) is controlled by the temperature detection of the cold wire, which shifts the position of the minimum temperature to the cold wire when the furnace temperature is identical to the cold wire temperature [32].

\subsection{Application and experimental procedure}

Even though the equipment can also be applied for investigating melting behaviour of liquid slags [49-51], it is mainly used to characterize the crystallization behaviour of liquid slags. Three possible approaches can be used to investigate the crystallization behaviour of mould slags [52]: isothermal or continuous cooling experiments using SHTT set-up and experiments with different thermal gradients using DHTT equipment. For the isothermal investigations, the slag is liquefied either within one SHTT $[21,45,52]$ or between both DHTT thermocouples $[28,32,52]$ and quenched to the desired temperatures below the melting point; it is held until no further crystallization can be observed. During the test, pictures of the sample in defined time intervals are taken and then evaluated to create time-temperature-transformation (TTT) diagrams for relevant crystallinities (e.g. $0.5 \%$ or $95 \%$ for the start or end of crystallization, respectively). The same set-up is used to develop continuous cooling transformation (CCT) diagrams. After the slag surrounding one thermocouple or between two thermocouples is heated (e.g. to $1773 \mathrm{~K}$ ), it is cooled at selected rates. The start and end, or possibly further arbitrary degrees of crystallization, are marked in the plot. To simulate the near-service conditions, DHTT is applied. The slag after liquefaction is stretched between two thermocouples, and one side is quenched to $827 \mathrm{~K}$ or a similar temperature representing the mould 
side, while the other is either held or cooled at a defined cooling rate simulating the cooling of the strand side [52, 53]. Kölbl et al. [32] defined a distance of $3 \mathrm{~mm}$ between the thermocouples.

Due to the formation of crystals out of the glassy mould flux within the continuous casting process with increasing interface thermal resistance, Zhou et al. [54] studied devitrification of two kinds of mould slags with a $\mathrm{CaO} /$ $\mathrm{SiO}_{2}$ ratio of 0.60 and 3.88 , respectively. The samples were liquefied and homogenized at $1773 \mathrm{~K}$ within SHTT-wire, then quenched to room temperature to obtain glassy phase and heated with the rates of $5,10,20$ and $30^{\circ} \mathrm{C} / \mathrm{min}$, respectively. The temperatures of first crystals precipitating out of the glassy phases are detected, and continuous heating transformation (CHT) diagrams are plotted.

The main application field of DHTT is in situ observation of the slag film structure under near-service conditions [28, 32, 52, 53]. Some scholars [55-57] also exposed the slags to certain temperature gradients and varied the humidity of the atmosphere to investigate the effect of water vapour on crystallization. Furthermore, the heat transfer through a completely glassy or crystalline slag film has already been measured [2, 58]. Another possible application is to study the effect of bubble formation [59] and subsequent dissolution when different external electrical potentials are applied to liquid silicates [30].

\subsection{Data evaluation}

For SHTT investigations, the depicted pictures of the samples are evaluated by calculating the crystallinity, which is defined as the crystallized volume percentage, from the crystallized as well as the total slag film area. From these results, the time required to achieve given crystallinities is determined and presented in a TTT diagram (Fig. 3a, c). The same procedure is carried out to create CCT or CHT diagrams (Fig. 3b-d). Here, the cooling rate or the heating rate, respectively, is represented and the start and in some cases the end of crystallization is marked (e.g. Fig. 3b) [41].

Thus far, DHTT results have mainly been represented via pictures taken during the experiments over time, and a partitioning of the slag according to the morphology of the crystals is depicted within these images [28]. This approach does not allow for a simple comparison of the crystallization behaviours of different slag compositions. Therefore, a new data analysis method as well as new representation of the results has been implemented [32]. For image editing, selected pictures from the experiment representing the crystallization procedure are evaluated with respect to the crystalline fraction. For this purpose, the crystallized domain
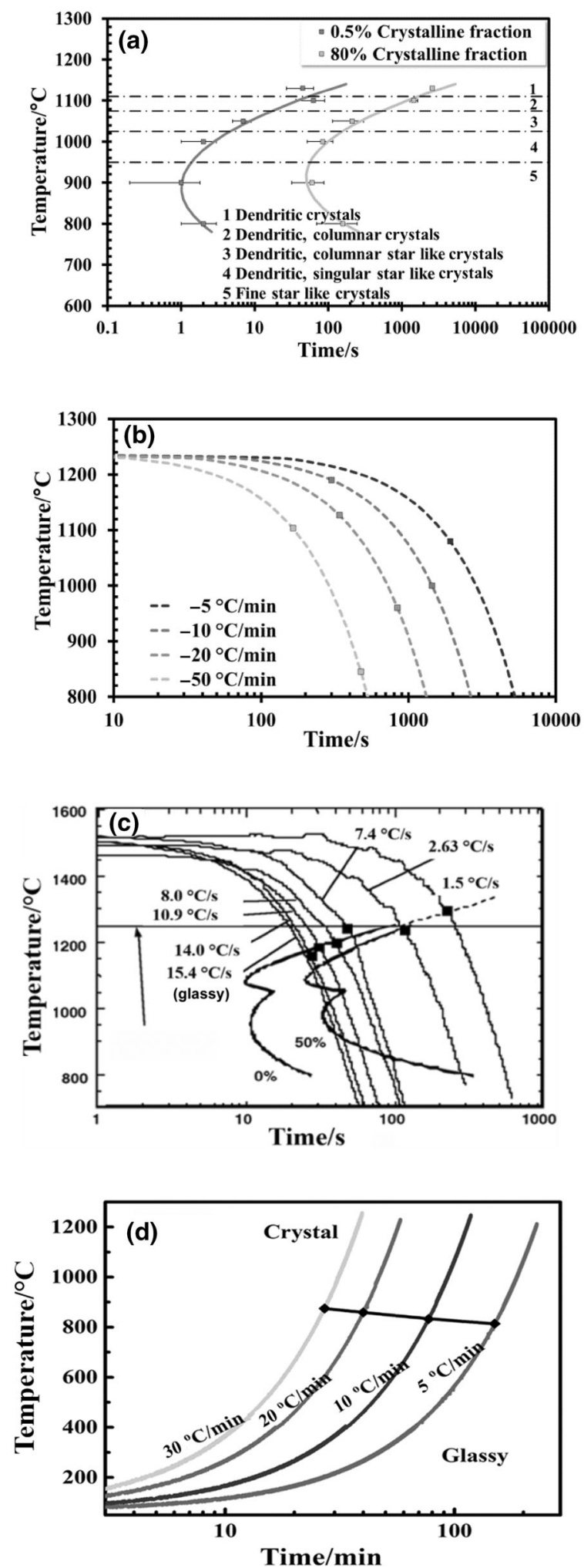

Fig. 3 TTT diagram (a) and related CCT diagram (b) for synthetic $\mathrm{Na}_{2} \mathrm{O}-\mathrm{CaO}-\mathrm{Al}_{2} \mathrm{O}-\mathrm{SiO}_{2}$ slag (adapted from Ref. [41]), TTT and CCT diagrams for an industrial mould flux (c) (adapted from Ref. [49]) and $\mathrm{CHT}$ of conventional $\mathrm{CaO}-\mathrm{SiO}_{2}$-based mould flux (d) (adapted from Ref. [54]) 
as well as the total slag area is determined. Because of partly insufficient contrast between the crystals and the platinum wire or the remaining liquid slag, a totally automated procedure is not yet possible. Manual recolouring of the original picture with a special image editing program is necessary for determining the crystalline area. Based on this information, the absolute crystallinity $(c)$ is calculated from the ratio between the crystallized area at a given time and the total area. These results are summarized within a diagram for all temperature gradients and their dependence on time. Another option to quantitatively represent the results is discretization of the slag film images into $0.1-\mathrm{mm}$ slices. First, for any arbitrary slice and elapsed time, the maximum crystalline fraction $\left(c_{\max }\right.$, i.e. the steady state achieved after a sufficient crystallization time) and the absolute crystallinity at any elapsed time $t$ are determined. Then, the relative crystallinity $\left(c_{\mathrm{r}}\right.$, the ratio of the crystallized area in a given slice at $t$ to the maximum crystallized area in the same) is calculated. The value of $c_{\max }$ representing the steady state can be depicted as a function of its distance from the cold wire (Fig. 4). Certain relative crystallinities have been defined (e.g. $0.5 \%$ for the start and $95 \%$ for the end of crystallization) and are plotted as functions of $t$. From this relationship, the associated time necessary to form the defined $c_{\mathrm{r}}$ value is identified. Thus, this time can be related to the position within the slag film (Fig. 5). If the volume nucleation only plays a minor role, the crystal growth rate $(v)$ is calculated from the crystalline area $(A)$, the viable perimeter $(U)$ and the elapsed time, according to Eq. (1) [32]:

$v=\frac{1}{U} \cdot \frac{\mathrm{d} A}{\mathrm{~d} t}$

\section{Results and discussion}

\subsection{Single hot thermocouple technique}

SHTT is mainly used to study the crystallization behaviour of mould slags under isothermal conditions to create either TTT or CCT diagram. Examples are given in Fig. 3 for a $\mathrm{Na}_{2} \mathrm{O}-\mathrm{CaO}-\mathrm{Al}_{2} \mathrm{O}_{3}-\mathrm{SiO}_{2}$ slag with a $\mathrm{CaO} / \mathrm{SiO}_{2}$ ratio of 1 , 4 wt. $\% \mathrm{Al}_{2} \mathrm{O}_{3}$ and 6 wt. $\% \mathrm{Na}_{2} \mathrm{O}$ and for an industrial mould flux [41, 49]. For these slags, the start of crystallization $(0.5 \%$ crystallinity) could be observed for all investigated temperatures. This was not the case for the end of crystallization (95\% crystallinity). Here, 95\% crystallinity could only be observed for temperatures close to the nose temperature. Away from this temperature, crystalline fractions of only $80 \%$ for the slag in Fig. 3a and solely $50 \%$ for the one in Fig. $3 \mathrm{c}$ were achieved within reasonable experimental time. Thus, these results defined the possible maximum crystalline fractions, which can be plotted in the diagrams for all investigated temperatures.
In quenching experiments, different crystal morphologies were obtained. Thus, a partitioning of the diagram according to the morphologies formed within a certain temperature range was possible. At lower temperatures, for all investigated mould slags, the precipitation of relatively small crystals within the total slag film occurs simultaneously. In contrast, at temperatures close to the liquidus temperature of the flux, columnar or dendritic crystals are formed in contact with the platinum wire and grow towards the centre. In between, several combinations of different crystal shapes may be observed, resulting in further detailing of the diagram (e.g. Fig. 3a). Nevertheless, some samples only show a separation into three areas. $\mathrm{Li}$ et al. [60] have reported similar results. For most mould slag compositions, the nose of TTT diagrams is observed within a few seconds and at temperatures between 1173 and $1373 \mathrm{~K}[29,39,61]$. In some cases, a second nose appears, indicating the temperature-dependent formation of different mineral phases [39, 49, 53].

$\mathrm{Cramb}$ [52] investigated the influence of humidity on the crystallization of $\mathrm{CaO}-\mathrm{Al}_{2} \mathrm{O}_{3}$ and $\mathrm{CaO}-\mathrm{Al}_{2} \mathrm{O}_{3}-\mathrm{MgO}$ slags. Water pressures of 3141, 4256 and $5472 \mathrm{~Pa}$ were selected, representing moisture-saturated air at 298, 303 and $308 \mathrm{~K}$, respectively. For $\mathrm{CaO}-\mathrm{Al}_{2} \mathrm{O}_{3}$ slag in the presence of humidity, the nucleation rate increased and TTT curve is shifted towards shorter elapsed time as well as towards higher temperatures. Additionally, an increase in the crystal growth rate is observed with increasing relative humidity. In contrast, the second slag exhibits different behaviours. In this case, at temperatures lower than $1373 \mathrm{~K}$, an increase in crystallinity is detected. However, for the temperature range between 1373 and $1523 \mathrm{~K}$, the crystallinity is not affected. In addition, for temperatures higher than $1523 \mathrm{~K}$, the crystallization process is impeded. Orrling et al. [55, 56] have reported similar results for a mould slag. Furthermore, they also investigated the influence of dry air on this sample after it crystallized under humidity. Immediately after dry air was introduced into the sample chamber, crystal dissolution and bubble formation occurred. The gas bubbles indicated the evaporation of water. A repeated exposure to humidity did not result in the reformation of crystals. These results reveal that humidity within the continuous casting process strongly affects the crystallization behaviour of mould slags and therefore must be considered for near-service investigations.

Further experiments were carried out to study the influence of oxide additions on the crystallization behaviour of mould slags, and TTT diagrams were obtained for different $\mathrm{Na}_{2} \mathrm{O}$ contents. An increase in $\mathrm{Na}_{2} \mathrm{O}$ content increased both the crystallization tendency and the growth rate. Therefore, the variation in $\mathrm{Na}_{2} \mathrm{O}$ content is one possible means of influencing the properties of the flux within the mould [56]. 
Zhou et al. [54] found that the initial crystallization temperature during the heating of glassy solidified mould fluxes increases with increasing heating rate (Fig. 3d). Depending on the chemical composition of the investigated mould fluxes and the heating rate, it could be detected between 1086 and $1245 \mathrm{~K}$. Kinetic analysis was carried out by calculating Mo exponent, the effective Avrami exponent and the Ozawa exponent. Defined values of the Ozawa exponents are related to certain crystallization mechanisms. Thus, the mechanisms could be identified and were confirmed by SHTT and scanning electron microscopy (SEM) analysis.

\subsection{Double hot thermocouple technique}

DHTT is used to experimentally characterize the temperature gradient within the mould flux by partly simulating the downward movement of the slag film with the strand, which is realized by cooling the hot wire with a defined

Table 1 Chemical compositions of slags investigated by DHTT $[32,63]$

\begin{tabular}{llrrr}
\hline Composition & MS 1 & MS 2 & MS 3 & MS 4 \\
\hline $\mathrm{GeO} /$ wt.\% & 80.0 & & & \\
$\mathrm{~K}_{2} \mathrm{O} /$ wt.\% & 20.0 & & & \\
$\mathrm{CaO} /$ wt.\% & & 30.2 & 37.1 & 32.4 \\
$\mathrm{SiO}_{2} /$ wt.\% & & 37.8 & 30.9 & 49.6 \\
$\mathrm{TiO}_{2} /$ wt.\% & & 8.8 & 8.8 & \\
$\mathrm{Na}_{2} \mathrm{O} /$ wt.\% & & 8.0 & 8.0 & \\
$\mathrm{~B}_{2} \mathrm{O}_{3} /$ wt.\% & & 5.0 & 5.0 & \\
$\mathrm{MgO}_{\mathrm{wt}} \%$ & & 4.5 & 4.5 & 6.9 \\
$\mathrm{Al}_{2} \mathrm{O} / \mathrm{wt} \%$ & 3.5 & 3.5 & 11.2 \\
$\mathrm{Li}_{2} \mathrm{O} /$ wt.\% & & 1.2 & 1.2 & \\
$\mathrm{FeO} /$ wt.\% & & 1.0 & 1.0 & \\
$\mathrm{CaO} / \mathrm{SiO}$ & & 0.8 & 1.2 & 0.7 \\
\hline
\end{tabular}

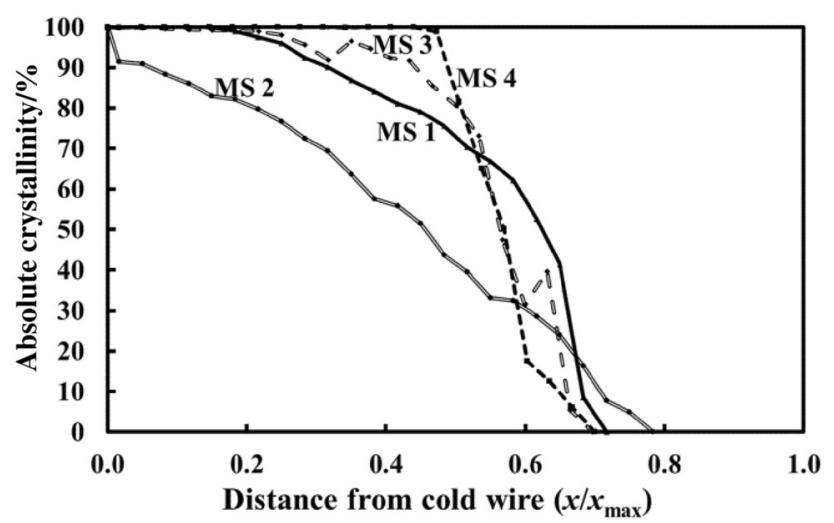

Fig. 4 Dependence of absolute crystallinity on position within slag film at $T_{\max }$ of $973 \mathrm{~K}$ (adapted from Ref. [63]) cooling rate. For all cases, the first crystals precipitate in contact with the cold wire and grow in the direction of higher temperatures. In some cases, equiaxed crystals are formed in contact with the liquid [52, 59, 62].

To calculate the temperature distribution between the two wires stretching the slag film, Zhou et al. [48] used the commercially available computation fluid dynamics software Fluent. The calculations showed that the minimum temperature occurs somewhere in the middle of the slag film and not at the cold wire as intended. According to the simulation results, when crystals are formed in the centre of the slag film, a higher thermal resistance in the middle of the flux is introduced, lowering the heat flux across the sample. This study encouraged the development of modified equipment to overcome the disadvantage of a minimum temperature located in the middle of the slag film. With the modified DHTT [32], the comparison of mould slag crystallization for different slag compositions is realized. The chemical compositions of the slags related to the results presented in Figs. 4-7 are summarized in Table 1.

Here, synthetic slags were chosen, and the maximum temperature for each slag was selected based on its dependence on the respective liquidus temperature. To reduce evaporation of volatile components, the maximum temperature $\left(T_{\max }\right)$ was set to only slightly exceed the liquidus temperature. Nevertheless, due to the standardization of the distance (distance within the slag film from the cold wire, $x$, related to the maximum distance of $3 \mathrm{~mm}$, $\left.x_{\max }\right)$, the results can still be used for comparison. For the investigation of the samples given in Table 1, the following maximum temperatures were selected: $1423 \mathrm{~K}$ for MS 1 and $1573 \mathrm{~K}$ for MS 2, MS 3 and MS 4. From the graphical representation of the maximum absolute crystallinity (Fig. 4), the minimum distance from the cold wire where crystals are no longer formed is detected as a function of the temperature gradient. As congruent solidification

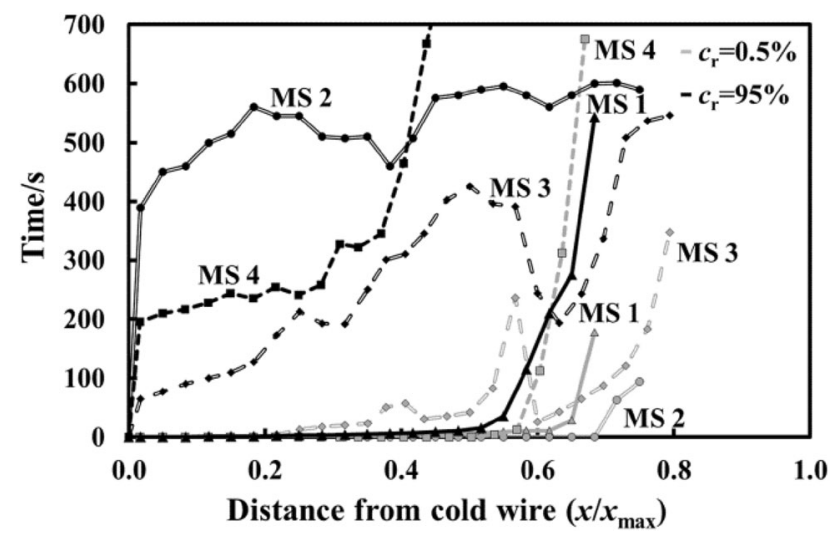

Fig. 5 Dependence of time for start $\left(c_{\mathrm{r}}=0.5 \%\right)$ and end $\left(c_{\mathrm{r}}=95 \%\right)$ of crystallization on position within slag film at $T_{\max }$ of $973 \mathrm{~K}$ (adapted from Ref. [63]) 


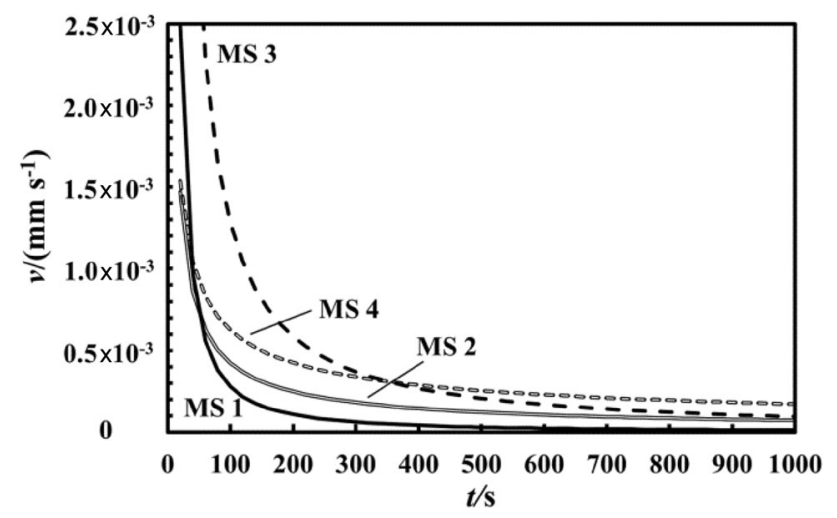

Fig. 6 Dependence of crystal growth rate on experimental time at $T_{\max }$ of $973 \mathrm{~K}$ (adapted from Ref. [63])

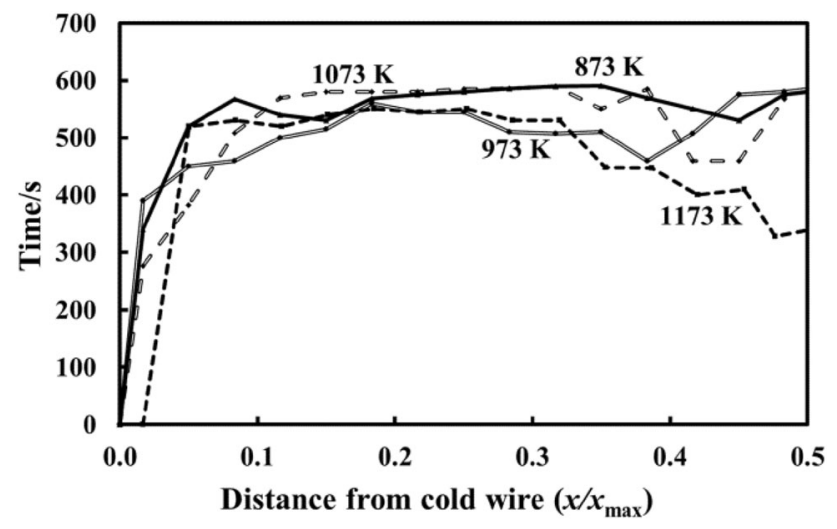

Fig. 7 Dependence of time for end of crystallization $\left(c_{\mathrm{r}}=95 \%\right)$ on position within slag film for MS 2 (adapted from Ref. [63])

behaviour (e.g. MS 1) results in a sharp decrease in the curve at the position representing its melting point, a smoother decrease indicates an incongruent solidification in which diffusion is the rate-limiting step. In this case, $100 \%$ absolute crystallinity is only detected in close proximity to the cold wire (e.g. MS 2). A not strictly monotonous curve progression indicates nucleation of crystals within the slag film, which are then transported throughout the liquid (e.g. MS 2 and MS 3).

For all of the investigated samples and temperature gradients, the highest crystal growth rates were calculated at the very beginning for slags showing congruent crystallization behaviour (MS 1). Afterwards, this rate decreases to even less than the rates of crystals where diffusion plays an essential role (Fig. 6). The diagrams representing the start of crystallization $\left(c_{\mathrm{r}}=0.5 \%\right)$ reveal that either volume nucleation in the slag film or surface nucleation at the platinum/slag interface occurs (see Fig. 5). In the case of a continuous rise in the curve progression with increasing distance from the cold wire (MS
1), crystals precipitate in contact with the platinum wire. In contrast, curves showing stepwise shapes indicate volume nucleation and the formation of crystalline isles within the liquid phase (MS 3). If the slag crystallizes congruently, its curve representing the end of crystallization $\left(c_{\mathrm{r}}=95 \%\right)$ is similar to that representing its start $\left(c_{\mathrm{r}}=0.5 \%\right)$; it only shifts to a longer elapsed time (see MS 1 in Fig. 5). An opposite curve characteristic is evident for incongruently solidifying slags. Here, a sudden rise in the elapsed time is detected in close proximity to the cold wire, followed by a smooth progression until it approaches the position representing the liquidus temperature (e.g. MS 2). If the crystallization behaviour is dominated by volume nucleation followed by the formation of crystalline isles, which then move within the slag due to convection, the curve progressions of different temperature gradients are nearly the same in close contact with the cold wire (Fig. 7). Additionally, the farthest position from the cold wire still showing crystallization is nearly constant. If both volume and surface nucleation contribute substantially to the formation of crystalline isles, that part of the time $v s$. distance curve does not show strict monotonous behaviour, viz., a partly negative slope [32, 63].

\subsection{Evaluation of investigation methods}

For the characterization of the solidification of mould fluxes, several methods are applied. The selection of the appropriate method depends on the definition of the problem, the expected results, and the effort necessary and tolerable for the experimental procedure as well as for the data analysis. For the determination of the slag viscosity, viscometry is the only experimental method apart from calculations based on the chemical composition [64-67]. This equipment reveals not only the viscosity dependence on time but also the break temperature, which is related to the crystallization process. Therefore, it is also applied for mould slag development and for determining the effect of the chemical modification during the casting on slag properties. Due to an acceptable experimental effort, the application for incoming inspection is reasonable.

The simultaneous thermal analysis provides results within a relatively short time, and these results can easily be evaluated. Nevertheless, the informative value is limited to the crystallization temperature range, its intensity and the number of different solid phases. When more detailed information is required, the cold finger test can be applied. Nevertheless, with this method, only the end of the experiment can be observed. Therefore, SHTT is favoured by enabling a comparison via TTT or CCT curves and the calculation of the crystal growth rate. Furthermore, devitrification of glassy slag samples can be observed. With this 
method, the morphology of the precipitated crystals is also observed. The crystals can be subsequently investigated by $\mathrm{X}$-ray diffraction analysis or by SEM in conjunction with energy-dispersive microanalysis. To investigate the slag film under near-service conditions, DHTT is favoured. To simulate the conditions during the operation, knowledge of the actual on-site temperature distribution is advantageous. When this information is not available, estimated temperature gradients can be chosen. For both SHTT and DHTT, due to the quite low magnification, the crystallized area is measured. The crystallinity calculated from it should be regarded as a nominal value; crystalline areas may contain liquid phase not optically resolved between the individual crystals. The true crystallinity may therefore be lower than the calculated nominal one, which therefore acts as an upper limit.

According to the results summarized in this paper, the hot thermocouple technique features a wide field of application. Nevertheless, some restrictions remain. Because the slag is stretched to a thin rectangular film, the specific surface of the sample is very high. This facilitates evaporation of volatile components, especially fluorine and $\mathrm{Na}_{2} \mathrm{O}$. Thus, a slag different from its original composition can be investigated. Therefore, efforts to reduce the vaporization of these components are necessary. One possibility might be the generation of a defined overpressure within the sample chamber, which will reduce or even prevent evaporation. Most recently, efforts have been made to develop fluorine-free mould slags [14, 20, 42, 68-71]. When the slag contains just moderate amounts of alkalis, its chemical composition varies only slightly from the original composition. This equipment reveals the necessary results to characterize and further improve these new mould slag systems. Additionally, due to the formation of a very thin slag film offering the observation of liquids with small amounts of colouring oxides, slag films collected from the continuous casting process during the tail-out can be investigated to detect the effect of possible interactions between the slag and the liquid steel on the crystallization behaviour. One main disadvantage is the rather time-consuming evaluation procedure. Therefore, the hot thermocouple technique is rather more suitable for application for research and development than for studies at production sites.

From the results, we draw the following conclusion: each of the aforementioned methods provides necessary information for a detailed characterization of the solidification behaviour of mould slags. Therefore, none of them is generally favoured. A critical examination between informative value and effort required for the experimental procedure and the data evaluation enables the selection of the most appropriate method.

\section{Conclusion}

In the continuous casting process of steels, crystallization of mould slags is of main interest, because the slag film structure mainly influences the horizontal heat flux. Thus, in this paper, different methods for investigating the crystallization behaviour of mould slags are reviewed. However, DTA, viscometer, CSLM and cold finger test reveal necessary information, and the main focus lies on the SHTT/DHTT device, the latter enabling in situ observation of the slags under near-service conditions. Continual improvements in the set-up help to overcome the disadvantages of a minimum temperature located within the slag film due to heat loss to the environment from the sample surface and enable the observation of slags with low amounts of colouring oxides. Proper display formats were developed facilitating the comparison of different slag compositions: the maximum crystallization as well as the time to achieve defined crystallinities in dependence on the position within the slag film between the hot wire, representing the strand side, and the cold wire, representing the mould. Furthermore, crystallization growth rates are calculated in dependence on the experimental time. Despite the advantages of this experimental method, it has to be considered that it is time-consuming to comprehensively characterize the crystallization behaviour of slags with SHTT/ DHTT. Thus, these devices are only reasonable for research and development and are not generally favoured. Based on the relevance of expected results and effort for experimental procedure, the most appropriate method can be selected.

Acknowledgements Open access funding is provided by Montanuniversitaet Leoben. This research programme of the "metallurgical competence centre" (K1-MET) is supported within the Austrian programme for competence centres, COMET (Competence Centre for Excellent Technologies), with funds from the Federal Ministry for Transport, Innovation and Technology; the Federal Ministry of Economy; the province of Upper Austria and Styria; the Styrian Business Promotion Agency; and the Tyrol and the Tyrolian Future Foundation.

Open Access This article is distributed under the terms of the Creative Commons Attribution 4.0 International License (http://crea tivecommons.org/licenses/by/4.0/), which permits unrestricted use, distribution, and reproduction in any medium, provided you give appropriate credit to the original author(s) and the source, provide a link to the Creative Commons license, and indicate if changes were made.

\section{References}

[1] K.C. Mills, A.B. Fox, R.P. Thackray, Z. Li, Proceedings of the VII International Conference on Molten Slags Fluxes and Salts, The South African Institute of Mining and Metallurgy, Johannesburg, South Africa, 2004, pp. 713-722. 
[2] Y. Kashiwaya, K. Ishii, ISIJ Int. 42 (2002) 71-79.

[3] E. Bachner, M. Ussar, Stahl Eisen 96 (1976) 185-190.

[4] P. Grieveson, S. Bagha, N. Machingawuta, K. Liddell, K.C. Mills, Ironmak. Steelmak. 15 (1988) 181-186.

[5] C.A. Pinheiro, I.V. Samarasekera, J.K. Brimacombe, Iron Steelmak. 22 (1995) 37-39.

[6] P. Tang, C.S. Xu, G.H. Wen, Y.H. Zhao, X. Qi, J. Iron Steel Res. Int. 15 (2008) No. 4, 7-11.

[7] J.A. Kromhout, R.C. Schimmel, Ironmak. Steelmak. 45 (2018) 249-256.

[8] T.M. Flores F., S. Rodríguez A., F. Ortega C., A.H. Castillejos E., Metall. Mater. Trans. B 49 (2018) 2633-2648.

[9] J.M. González de la C., T.M. Flores F., A.H. Castillejos E., Metall. Mater. Trans. B 47 (2016) 2509-2523.

[10] Y.G. Maldonado, A.H. Castillejos E., Mater. Des. 83 (2015) $728-735$.

[11] Y.G. Maldonado, F.A. Acosta, A.H. Castillejos, B.G. Thomas, Iron Steel Technol. 10 (2013) 65-75.

[12] G. Fischer, A. Golloch, J. Kasajanow, Steel Res. Int. 67 (1996) 479-484.

[13] E. Brandaleze, E. Benavidez, L. Santini, Acta Microsc. 22 (2013) 42-48.

[14] H. Nakada, K. Nagata, ISIJ Int. 46 (2006) 441-449.

[15] J.L. Li, Q.S. Shu, X.M. Hou, K. Chou, ISIJ Int. 55 (2015) 830-836.

[16] V. Kircher, I. Marschall, N. Kölbl, H. Harmuth, 2014 Proceedings-8th European Continuous Casting Conference, The Austrian Society for Metallurgy and Materials, Graz, Austria, 2014, pp. 1050-1059.

[17] Z. Wang, Q.F. Shu, K. Chou, ISIJ Int. 55 (2015) 709-716.

[18] D. Wang, M. Jiang, C. Liu, P. Shi, Y. Yao, H. Wang, J. Rare Earths 23 (2005) 68-72.

[19] X. Li, K. Wu, X. Zhou, F. Zhang, B.Z. Feng, G.L. Xiong, J. Iron Steel Res. 18 (2006) No. 7, 25-29.

[20] L. Zhou, H. Li, W. Wang, I. Sohn, Steel Res. Int. 88 (2017) 1600459.

[21] D. dos Reis Silva, A.C.F. Vilela, N.C. Heck, H.P. Heller, O. Volkova, Steel Res. Int. 89 (2018) 1700246.

[22] J.W. Cho, H. Shibata, J. Non-Cryst. Solids 282 (2001) 110-117.

[23] C. Orrling, S. Sridhar, A.W. Cramb, ISIJ Int. 40 (2000) 877-885.

[24] Z.T. Zhang, G.H. Wen, J.L. Liao, S. Sridhar, Steel Res. Int. 81 (2010) 516-528.

[25] J.Y. Park, J.W. Ryu, I. Sohn, Metall. Mater. Trans. B 45 (2014) $1186-1191$.

[26] S. Michelic, J. Goriupp, S. Feichtinger, Y.B. Kang, C. Bernhard, J. Schenk, Steel Res. Int. 87 (2016) 57-67.

[27] K.L.S. Assis, P.C. Pistorius, in: R.G. Reddy, P. Chaubal, P.C. Pistorius, U. Pal (Eds.), Advances in Molten Slags, Fluxes, and Salts: Proceedings of the 10th International Conference on Molten Slags, Fluxes and Salts, Springer, 2016, pp. 307315.

[28] Y. Kashiwaya, C.E. Cicutti, A.W. Cramb, K. Ishii, ISIJ Int. 38 (1998) 348-356.

[29] Y. Kashiwaya, C.E. Cicutti, A.W. Cramb, K. Ishii, ISIJ Int. 31 (1998) 357-365.

[30] M. Nakata, A.W. Cramb, Metall. Mater. Trans. B 39 (2008) 649-654.

[31] Q. Shu, Z. Wang, J.L. Klug, K. Chou, P.R. Scheller, Steel Res. Int. 84 (2013) 1138-1145.

[32] N. Kölbl, I. Marschall, H. Harmuth, Metall. Mater. Trans. B 49 (2018) 1898-1908.

[33] F. Ordway, J. Res. Natl. Bur. Stand. 48 (1952) 152-158.

[34] J.H. Welch, J. Sci. Instrum. 31 (1954) 458-462.

[35] C. Orrling, S. Sridhar, A.W. Cramb, High Temp. Mater. Proc. 20 (2000) 195-199.
[36] C.Y. Zhu, C.J. Liu, D.Y. Wang, M.F. Jiang, J. Northeast. Univ. (Nat. Sci.) 25 (2004) 988-990.

[37] B. Jia, J.L. Shi, G.H. Wen, P. Tang, Y.J. Wu, F.L. He, J.Q. Li, J. Iron Steel Res. 18 (2006) No. 2, 21-23.

[38] Y. Kashiwaya, T. Nakauchi, K.S. Pham, S. Akiyama, K. Ishii, ISIJ Int. 47 (2007) 44-52.

[39] G.H. Wen, H. Liu, P. Tang, J. Iron Steel Res. Int. 15 (2008) No. 4, 32-37.

[40] C.Q. Ji, B. Xie, Y. Lei, J. Diao, F. Qi, J. Univ. Sci. Technol. Beijing 32 (2010) 306-311.

[41] N. Kölbl, I. Marschall, H. Harmuth, J. Mater. Sci. 46 (2011) 6248-6254.

[42] J.L. Klug, R. Hagemann, N.C. Heck, A.C.F. Vilela, H.P. Heller, P.R. Scheller, Steel Res. Int. 83 (2012) 1186-1193.

[43] Y.X. Sun, J. Li, X.D. Wang, Z.T. Zhang, Metall. Mater. Trans. B 45 (2014) 1446-1455.

[44] W. Yan, W.Q. Chen, Y.D. Yang, C. Lippold, A. McLean, ISIJ Int. 55 (2015) 1000-1009.

[45] S. Esfahani, M. Barati, J. Non-Cryst. Solids 436 (2016) 35-43.

[46] Y. Lei, B. Xie, W.H. Ma, J. Iron Steel Res. Int. 23 (2016) 322-328.

[47] B.X. Lu, W.L. Wang, J. Li, H. Zhao, D.Y. Huang, Metall. Mater. Trans. B 44 (2013) 365-377.

[48] L.J. Zhou, W.L. Wang, R. Liu, B.G. Thomas, Metall. Mater. Trans. B (2013) 1264-1279.

[49] C. Orrling, A.W. Cramb, A. Tilliander, Y. Kashiwaya, Iron Steelmak. 27 (2000) 53-63.

[50] K. Prapakorn, S. Seetharaman, in Steelmak. Conf. Proc. 84, Iron and Steel Society, Warrendale, USA, 2001, pp. 357-368.

[51] C. Orrling, A. Tilliander, Y. Kashiwaya, A.W. Cramb, Steelmak. Conf. Proc. 82, Iron and Steel Society, Warrendale, USA, 1999, pp. 417-424.

[52] A.W. Cramb, Final Report of AISI/DOE Technology Roadmap Program (2003-05) [2018-07-16]. http://steeltrp.com/finalre ports/finalreports/9903NonPropFinalReport.pdf.

[53] J. Yang, Y. Ciu, L. Wang, Y. Sasaki, J. Zhang, O. Ostrovski, Y. Kashiwaya, Steel Res. Int. 86 (2015) 636-643.

[54] L.J. Zhou, H. Li, W.L. Wang, J. Chang, Metall. Mater. Trans. B 49 (2018) 3019-3029.

[55] C. Orrling, A.W. Cramb, Metall. Mater. Trans. B 31 (2000) 403-406.

[56] C. Orrling, S. Sridhar, Y. Kashiwaya, A.W. Cramb, Proceedings of the 58th Electric Furnace Conference and 17th Process Technology Conference, Iron and Steel Society, Warrandale, USA, 2000, pp. 211-221.

[57] J.Y. Baek, J.W. Cho, S.H. Kim, Metall. Mater. Trans. B 47 (2016) 32-36.

[58] W.L. Wang, K.Z. Gu, L.J. Zhou, F.J. Ma, I. Sohn, D.J. Min, H. Matsuura, F. Tsukihashi, ISIJ Int. 51 (2011) 1838-1845.

[59] C. Orrling, A. Tilliander, Y. Kashiwaya, A.W. Cramb, in: 82nd Steelmaking Conference Proceedings, Iron and Steel Society, Warrandale, USA, 1999, pp. 417-424.

[60] J. Li, W.L. Wang, J. Wei, D.Y. Huang, H. Matsuura, ISIJ Int. 52 (2012) 2220-2225.

[61] Z. Zhang, G.H. Wen, Y. Zhang, Int. J. Miner. Metall. Mater. 18 (2011) 150-158.

[62] C. Orrling, Y. Fang, N. Phinichka, S. Sridhar, A.W. Cramb, JOM 51 (1999) [2018-08-12]. https://www.tms.org/pubs/jour nals/jom/9907/orrling/orrling-9907.html.

[63] N. Kölbl, I. Marschall, V. Kircher, H. Harmuth, in: Proceedings of the 7th International Congress Sci. Technol. Steelmak., Italian Association for Metallurgy, Venice, Italy, 2018.

[64] P.V. Riboud, Y. Roux, L.D. Lucas, H. Gaye, Fachber. Huettenpraxis Metallweiterver. 19 (1981) 859-869.

[65] T. Iida, H. Sakai, Y. Kita, K. Shigeno, ISIJ Int. 40 (2000) S110 S114. 
[66] G. Urbain, Steel Res. Int. 58 (1987) 111-116.

[67] K.C. Mills, S. Sridhar, Ironmak. Steelmak. 26 (1999) 262-268.

[68] G. Wen, P. Tang, L. Zhang, Y. Liu, S. Miao, AIST/TMS Proceedings: Mater. Sci. Technol. 2, New Orleans, USA, 2004, pp. 69-73.

[69] A.B. Fox, K.C. Mills, D. Lever, C. Bezerra, C. Valadares, I. Unamuno, J.J. Laraudogoitia, J. Gisby, ISIJ Int. 45 (2005) 1051-1058.
[70] Z. Wang, Q. Shu, K. Chou, Steel Res. Int. 84 (2013) 766-776.

[71] I. Marschall, X. Yang, H. Harmuth, in: R. Reddy, P. Chaubal, P. Pistorius, U. Pal (Eds.), Proceedings of the 10th International Conference on Molten Slags, Fluxes, and Salts, The Minerals, Metals \& Materials Society, Pittsburg, USA, 2016, pp. 299-306. 